PAPER

\title{
The longer term outcome of children born to mothers with epilepsy
}

\section{N Adab, U Kini, J Vinten, J Ayres, G Baker, J Clayton-Smith, H Coyle, A Fryer, J Gorry, J Gregg, G Mawer, P Nicolaides, L Pickering, L Tunnicliffe, D W Chadwick}

See Editorial Commentary, p 1517

J Neurol Neurosurg Psychiatry 2004:75:1575-1583 doi: 10.1136/innp.2003.029132

Objectives: To determine the prevalence of cognitive delay and possible associated dysmorphic features in children exposed to antiepileptic drugs (AEDs) in utero.

Design: Retrospective study of children born to mothers with epilepsy.

Setting: Regional epilepsy clinics in Liverpool and Manchester, UK.

See end of article for authors' affiliations

Participants: Children aged between 6 months and 16 years born to mothers with epilepsy.

Main outcome measures: Structured interviews, hospital records, clinical examination, and psychometric tests (Wechsler) were used to assess exposure and intelligence quotient (IQ). Blinded assessment of photographs was used to score children with characteristic dysmorphic features.

Correspondence to: $\mathrm{N}$ Adab, The Walton Centre for Neurology and Neurosurgery, Lower Lane, Fazakerley, Liverpool, L9 7ப, UK; n.adab@virgin.net

Received

26 September 2003

In revised form 2 June 2004

Accepted for publication

18 July 2004

Results: A total of 249 children aged 6 and over were studied: 41 were exposed to sodium valproate, 52 to carbamazepine, 21 to phenytoin, 49 to polytherapy, and 80 were unexposed. Mean verbal IQ was significantly lower in the valproate group compared to unexposed and other monotherapy groups. Multiple regression analysis showed that both valproate exposure and frequent tonic-clonic seizures in pregnancy were significantly associated with a lower verbal IQ despite adjusting for other confounding factors. There was a significant negative correlation between dysmorphic features and verbal IQ in children exposed to valproate.

Conclusions: This study identifies valproate as a drug carrying potential risks for developmental delay and cognitive impairment and is the first to suggest that frequent tonic-clonic seizures have a similar effect. Our results need to be interpreted with caution given their retrospective nature. Women with epilepsy need careful counselling about individual risk benefit of AED treatment before pregnancy.
$\mathrm{E}$ pilepsy is common and has a prevalence of 5.25 per $1000 .{ }^{1}$ One third of people with epilepsy are women of reproductive age and 1 in 200 women attending antenatal clinics are receiving antiepileptic drugs (AEDs). ${ }^{2}$ Both seizures during pregnancy and AED exposure in utero are thought to influence the poorer outcomes seen in children born to mothers with epilepsy.

AEDs have been associated with a two to three fold increase in major malformations in children exposed to AEDs in utero, compared to the general population..$^{4-6}$ Early reports of minor anomalies ${ }^{78}$ and cognitive delay ${ }^{8-10}$ alerted investigators to the possibility of longer term adverse effects. A characteristic pattern of minor anomalies may be specific to certain AEDs $^{811-13}$ and may be markers of underlying developmental problems. ${ }^{812-15}$ Others have argued that these anomalies may be associated with epilepsy itself. ${ }^{16}{ }^{17}$

Retrospective $^{1018-20}$ and prospective studies ${ }^{91-23}$ have documented a higher prevalence of early developmental delay in children born to women with epilepsy, but studies following children up to later years have been conflicting, ${ }^{24}{ }^{25}$ particularly as to the role of individual drugs. ${ }^{26-33}$

In this retrospective study of children born to mothers with epilepsy we report the developmental, neuropsychological, and dysmorphic features of children exposed to AEDs in utero, relative to children of women with epilepsy unexposed to AEDs. The aims were:

- To determine the prevalence of cognitive impairment in children exposed to AEDs in utero

- To identify drug specific effects

- To explore the association of dysmorphic features with cognitive impairment or developmental delay.

\section{METHODS}

\section{Study population}

Between January 2000 and May 2001, women with epilepsy with children aged 6 months to 16 years were identified from the Mersey Regional Epilepsy Clinic between 1989 and 1999 through a pilot survey, ${ }^{34}$ the Epilepsy Clinic at the Manchester Royal Infirmary between 1991 and 1999, and the antenatal clinic at St Mary's Hospital, Manchester between 1991 and 1999.

Women with a progressive neurological deficit, significant learning difficulty, or symptomatic generalised epilepsy were excluded. The study was approved by the northwest multicentre and local research ethics committees.

\section{Clinical assessment}

\section{Mothers}

A clinician conducted semi-structured interviews of mothers to ascertain information about their epilepsy and relevant pregnancy. Clinical records were used to confirm information. Epilepsy type was categorised into three groups: idiopathic generalised, localisation related, and unclassified epilepsy using the ILAE classification. ${ }^{35}$

Abbreviations: AEDs, antiepileptic drugs; AEN, additional educational needs; FACS, fetal anticonvulsant syndromes; FSIQ, full scale IQ; IGE, idiopathic generalised epilepsy; $I Q$, intelligence quotient; $L D$, learning difficulties; NART, National Adult Reading Test; PIQ, performance IQ; SES, socioeconomic status; SGSII, Schedule of Growing Skills II; VIQ, verbal IQ; WISC-III, Wechsler Intelligence Test for Children; $95 \% \mathrm{Cl}$, $95 \%$ confidence interval 
Table 1 Characteristics of mothers and their epilepsy

\begin{tabular}{|c|c|c|c|c|c|}
\hline Epilepsy type & Number (\%) & Maternal NART $(95 \% \mathrm{Cl})$ & $\begin{array}{l}\text { No. with one } \\
\text { child assessed }\end{array}$ & $\begin{array}{l}\text { No. with one } \\
\text { additional sibling }\end{array}$ & $\begin{array}{l}\text { No. with two } \\
\text { or more siblings }\end{array}$ \\
\hline Idiopathic generalised & $68(31)$ & 101.1 (98.2 to 103.9$)$ & 24 & 36 & 8 \\
\hline Localisation related & $141(64)$ & 99.6 (97.5 to 101.7$)$ & 66 & 60 & 15 \\
\hline Unclassified & $10(5)$ & 98.0 (87.1 to 108.9$)$ & 5 & 4 & 1 \\
\hline Total & 219 & 100.0 (98.3 to 101.7$)$ & 95 & 100 & 24 \\
\hline
\end{tabular}

\section{Children}

A semi-structured interview was used to collect data for each child on early development, behavioural problems, schooling, additional educational needs (AEN, defined as having a statement for AEN, being on the register for AEN, or requiring extra help in mainstream school), and the need for additional therapy including speech therapy.

Dysmorphic features, defined as cosmetic variations without disability, were recorded by an examiner at each centre, using a checklist of 30 features previously described for fetal anticonvulsant syndromes (FACS). ${ }^{36}$ Children's faces, profiles, hands, and feet were photographed. These were assessed by two geneticists and a paediatrician, who were unaware of the drug exposure of the children. The reviewers gave a consensus score for overall appearance on a scale of 0-10 for typical features of FACS. Scores were categorised as normal appearance (0), minor (0.5-3), moderate (4-6), and severe features of FACS (7-10).

Major malformations, defined as structural abnormalities requiring medical or surgical intervention to prevent disability, were recorded using the EUROCAT guidelines. ${ }^{37}$

\section{Neuropsychological tests}

Children aged between 6 and 16 years were blindly assessed by a neuropsychologist using the Wechsler Intelligence Test for Children (WISC-III) ${ }^{38}$ which provides a measure of full scale intelligence quotient (FSIQ) from a composite score of verbal IQ (VIQ) and performance IQ (PIQ). Psychomotor and cognitive development was assessed in children from birth to 5 years using the Schedule of Growing Skills II (SGSII). ${ }^{39}$ Maternal intellectual functioning was assessed using the National Adult Reading Test (NART) ${ }^{40}$

\section{Socioeconomic status}

Socioeconomic status for each child was classified according to the National Office of Statistics guidelines ${ }^{41}$ using the details of the father or the mother where the former were unavailable

\section{Statistical analysis}

For each outcome those exposed to specific monotherapy regimes or any polytherapy were compared to unexposed children.

The primary outcome was the IQ in children over 6 . The study had $90 \%$ power to detect a 10 point difference in IQ with unequal sample sizes ( 72 unexposed and 36 exposed). A one way analysis of co-variance with Bonferroni adjustment of significance level was used to compare mean FSIQ, VIQ, and PIQ between multiple groups and Student's $t$ test for two groups.

Linear regression was used to study explanatory factors for VIQ, PIQ, and FSIQ. Factors identified a priori included maternal age at birth, number of convulsive seizures during pregnancy, maternal epilepsy type, regular alcohol/smoking during pregnancy, pre-conceptual folic acid, family history of malformations and learning difficulties in a first degree relative, maternal FSIQ (as assessed by NART), and socioeconomic status. Spearmans correlation was used to examine correlation between dose of AEDs and IQ, and dysmorphic features and IQ.

Statistical analyses were undertaken using the SPSS statistics computer package (version 10).

\section{RESULTS}

Characteristics of the mothers, their pregnancies, and their children

From the 547 mothers approached, 219 (40\%) agreed to participate (169 from epilepsy clinics and 50 from the antenatal clinic) (table 1). Some $48 \%$ of the participating mothers (106) had responded to a pilot survey about their children's schooling. ${ }^{34}$

Table 2 Characteristics of pregnancies (frequencies are shown)

\begin{tabular}{|c|c|c|c|c|c|c|c|c|c|c|c|}
\hline \multirow[b]{2}{*}{$\begin{array}{l}\text { Drug exposure } \\
\text { in pregnancy }\end{array}$} & \multirow[b]{2}{*}{$\begin{array}{l}\text { Age } \geqslant 6 \\
\text { years }\end{array}$} & \multirow[b]{2}{*}{$\begin{array}{l}\text { Mean age } \\
\text { (SD) }\end{array}$} & \multirow[b]{2}{*}{$\begin{array}{l}\text { Age } \leqslant 5 \\
\text { years }\end{array}$} & \multirow[b]{2}{*}{$\begin{array}{l}\text { Mean age } \\
\text { (SD) }\end{array}$} & \multicolumn{3}{|c|}{ Maternal epilepsy } & \multicolumn{3}{|c|}{ Seizures during pregnancy } & \multirow[b]{2}{*}{ All (\%) } \\
\hline & & & & & $\begin{array}{l}\text { Idiopathic } \\
\text { generalised } \\
\text { epilepsy }\end{array}$ & $\begin{array}{l}\text { Local. } \\
\text { related }\end{array}$ & $\begin{array}{l}\text { Unclass- } \\
\text { ified }\end{array}$ & $\begin{array}{l}\text { None or } \\
\text { non- } \\
\text { convulsive }\end{array}$ & $\begin{array}{l}1-4 \\
\text { tonic- } \\
\text { clonic } \\
\text { seizures }\end{array}$ & $\begin{array}{l}5 \text { or more } \\
\text { tonic-clonic } \\
\text { seizures }\end{array}$ & \\
\hline Unexposed & 83 & $10.5(3.2)$ & 18 & $3.3(0.9)$ & 23 & 71 & 7 & 83 & 13 & 5 & 101 \\
\hline Monotherapy & 121 & $9.6(3.2)$ & 77 & $3(1.3)$ & 72 & 119 & 7 & 126 & 45 & 27 & 198 \\
\hline Carbamazepine & 52 & $9.5(3.2)$ & 42 & $3.0(1.2)$ & 21 & 72 & 1 & 55 & 22 & 17 & 94 (47) \\
\hline Phenytoin & 21 & $10.7(3.5)$ & 5 & $2.6(1.4)$ & 9 & 16 & 1 & 17 & 7 & 2 & $26(13)$ \\
\hline Valproate & 42 & $9.0(2.9)$ & 21 & $3.3(1.4)$ & 39 & 19 & 5 & 47 & 12 & 4 & $63(32)$ \\
\hline Other & 6 & $11.5(3.6)$ & 9 & $3.0(1.7)$ & 3 & 12 & 0 & 7 & 4 & 4 & $15(8)$ \\
\hline Polytherapy & 52 & $10(3.1)$ & 24 & $2.8(1.4)$ & 28 & 46 & 2 & 26 & 20 & 30 & 76 \\
\hline 2 AEDs & 39 & $10.2(3.2)$ & 19 & $2.8(1.3)$ & 20 & 36 & 2 & 19 & 17 & 22 & $58(76)$ \\
\hline 3 AEDs & 10 & $9.1(2.9)$ & 3 & 2.2 & 4 & 9 & 0 & 5 & 3 & 5 & 13 (17) \\
\hline 4 or more AEDs & 3 & 8.0 & 2 & 4 & 4 & 1 & 0 & 2 & 0 & 3 & $5(7)$ \\
\hline Including VPS* & 29 & $10.5(3.1)$ & 12 & $2.6(1.1)$ & 18 & 21 & 2 & 11 & 14 & 16 & $41(54)$ \\
\hline Excluding VPS* & 23 & $9.5(3.0)$ & 12 & $3.0(1.6)$ & 10 & 25 & 0 & 15 & 6 & 14 & $35(46)$ \\
\hline Total & 256 & $10.0(3.1)$ & 119 & $3.0(1.3)$ & 123 & 236 & 16 & 235 & 78 & 62 & 375 \\
\hline
\end{tabular}


Table 3 WISC scores for children aged 6 years or older by drug exposure

\begin{tabular}{|c|c|c|c|c|c|}
\hline AED regime & $n$ & Mean maternal IQ $(95 \% \mathrm{Cl})^{*}$ & Mean VIQ $(95 \% \mathrm{CI})$ & Mean PIQ $(95 \% \mathrm{Cl})$ & Mean FSIQ (95\% CI) \\
\hline $\begin{array}{l}\text { Unexposed } \\
\text { Monotherapy }\end{array}$ & 80 & 98.1 (95.6 to 100.7 ) & $90.9(87.2$ to 94.6$)$ & 90.2 (86.1 to 93.0 ) & 89.5 (85.5 to 93.4 ) \\
\hline Valproate & 41 & 98.3 (94.3 to 102.3 ) & 83.6 (78.2 to 89.0 ) & $94.0(88.9$ to 99.0$)$ & 87.2 (81.9 to 92.5$)$ \\
\hline Carbamazepine & 52 & 101.6 (98.6 to 104.6$)$ & 94.1 (89.6 to 98.5 ) & $89.4(84.8$ to 94.0$)$ & 91.1 (86.4 to 95.8 ) \\
\hline Phenytoin & 21 & 99.0 (94.5 to 103.4 ) & 98.5 (90.6 to 106.4 ) & 97.1 (91.7 to 102.6$)$ & 97.6 (90.3 to 105.0$)$ \\
\hline All & 120 & 99.5 (97.3 to 101.3 ) & 91.0 (87.9 to 94.1$)$ & $92.3(89.5$ to 95.1$)$ & 90.7 (87.7 to 93.8 ) \\
\hline \multicolumn{6}{|l|}{ Polytherapy } \\
\hline Including VPS & 28 & 97.4 (93.4 to 101.4 ) & 87.1 (81.6 to 92.7$)$ & 89.1 (83.2 to 94.9 ) & 86.8 (81.2 to 92.4$)$ \\
\hline Excluding VPS & 21 & 98.3 (93.6 to 103.1$)$ & 91.9 (85.6 to 98.2 ) & 89.1 (82.4 to 95.8 ) & 89.3 (83.5 to 95.2 ) \\
\hline All & 49 & 97.8 (94.9 to 100.7 ) & 89.2 (85.1 to 93.2 ) & 89.2 (85.1 to 93.2 ) & $87.9(83.9$ to 91.8$)$ \\
\hline All valproate exposed & 69 & 97.9 (95.5 to 100.7 ) & $85.0(81.2$ to 88.9$)$ & 92.0 (88.2 to 95.8$)$ & 87.0 ( 83.2 to 90.8 ) \\
\hline
\end{tabular}

There were a total of 375 children aged between 6 months and 16 years (mean age 7.7 years, SD 4.3). Their drug exposures are described in table 2 .

The reasons for non-exposure were pregnancy predating the diagnosis of epilepsy (52\%), seizure free mothers (34\%), and other reasons including non-compliance (14\%).

We have no evidence that drug exposure influenced the likelihood of inclusion. While we do not have information on the drug exposures of all non-participants, the subset of participants who responded to both the pilot survey ${ }^{34}$ and the current study does not suggest bias $(32 \%, 38 \%$, and $32 \%$ for valproate and carbamazepine monotherapy and unexposed, respectively). Furthermore, the distribution of drug exposures in this study conforms with that seen in cases collected for an ongoing prospective study (24\% of cases carbamazepine monotherapy, $20 \%$ valproate monotherapy, and 20\% unexposed).

\section{Developmental and cognitive outcomes}

\section{Children over the age of 6: Wechsler Intelligence} Scale

Of the 256 children, 249 completed the WISC (table 3). Two refused to take part, one was too old when recalled for testing, one was lost to follow up, and three were unable to complete the test due to behavioural problems, speech impairment, and severe learning difficulties, respectively.

The mean FSIQ was at the low end of the average range for children exposed to monotherapies and was similar to the mean score in unexposed children. Those exposed to polytherapies had a lower mean score than the unexposed and those exposed to monotherapies, but this was not statistically significant.

The mean PIQ was within or close to the average range in all drug groups, with no significant difference among the different exposures.

Table 4 Independent Student's $t$ test for comparisons between groups for VIQ

\begin{tabular}{|c|c|c|c|}
\hline Drug 1 & Drug 2 & $\begin{array}{l}\text { Mean difference in } \\
\text { VIQ }(95 \% \mathrm{Cl})\end{array}$ & $p$ \\
\hline $\begin{array}{l}\text { Valproate } \\
\text { monotherapy }\end{array}$ & Carbamazepine & $-10.5(-17.3$ to -3.6$)$ & 0.003 \\
\hline Valproate & $\begin{array}{l}\text { Phenytoin } \\
\text { monotherapy }\end{array}$ & $-14.9(-24.1$ to -5.6$)$ & 0.002 \\
\hline $\begin{array}{l}\text { Valproate } \\
\text { monotherapy }\end{array}$ & Unexposed & $-7.3(-13.6$ to -0.9$)$ & 0.025 \\
\hline $\begin{array}{l}\text { Polytherapy } \\
\text { with VPS }\end{array}$ & Unexposed & $-3.8(-10.7$ to 3.2$)$ & 0.281 \\
\hline $\begin{array}{l}\text { All valproate } \\
\text { exposed }\end{array}$ & Unexposed & $-5.9(-11.2$ to -0.6$)$ & 0.030 \\
\hline
\end{tabular}

VPS monotherapy is associated with a significantly lower VIQ compared to carbamazepine, phenytoin, and unexposed.
The mean VIQ was in the low average range in those exposed to VPS monotherapy and was significantly lower than the unexposed and other monotherapy drug groups, being on average 7 points lower (table 4). Those exposed to VPS as part of a polytherapy regime had a non-significant lower mean VIQ.

There was a greater proportion of children scoring in the low $(23 \%)$ and exceptionally low range $(7 \%)$ in the unexposed group than one would expect, potentially reflecting a bias introduced by mothers self selecting to participate in the study (fig 1). However, among those exposed to VPS monotherapy, the proportion of children scoring in the low $(20 \%)$ and exceptionally low range $(22 \%)$ was significantly greater than in the carbamazepine exposed group $\left(\chi^{2}\right.$ for trend 8.431, df l, $\mathrm{p}=0.004$ ).

The odds ratio for a VIQ of 69 or less compared to the unexposed group was significantly greater for VPS monotherapy $(3.5,95 \%$ CI 1.1 to 10.6$)$.
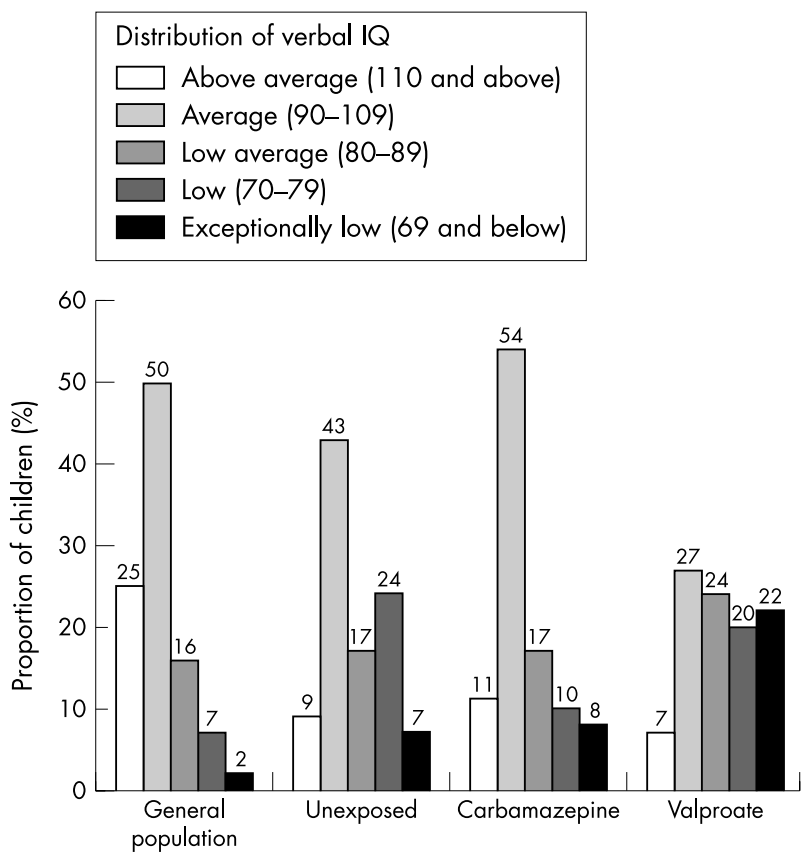

Figure 1 Distribution of $\mathrm{VIQ}$ according to monotherapy drug exposure in utero compared to the expected score in the general population. The WISC is an age standardised test which has been administered to a large representative sample of the UK general population, allowing norms to be determined from the results. The scales have a mean of 100 and SD of 15, and the expected distribution in the normal population is shown at the far left. ${ }^{38}$ 
A total of 88 younger siblings of 158 children aged 6 and over were also assessed. This could represent a source of bias. When the IQ scores were examined in the first born only, the results remained consistent with those from all children. Mean VIQ in first born children exposed to VPS $(\mathrm{n}=27,82.7$, $95 \%$ CI 75.6 to 90.0$)$ was significantly lower than the unexposed group $(\mathrm{n}=53,94.1,95 \%$ CI 89.7 to 98.5 , $\mathrm{p}=0.006)$ and those exposed to carbamazepine $(\mathrm{n}=27$, 95.5, $95 \%$ CI 87.9 to $103.0, \mathrm{p}=0.006$ ).

Exploration of factors predicting VIQ in the children Univariate linear regression analysis (table 5a) using all the a priori listed variables, showed that five factors were significantly associated with VIQ, but multiple regression analysis suggested only three factors: lower maternal IQ, valproate exposure, and five or more tonic-clonic seizures in pregnancy were independently predictive of a lower VIQ (table 5b). All variables were included in the final model if they reached a significance of $\mathrm{p}<0.1$ in univariate analysis or were considered clinically important. The numbers of mothers with regular alcohol were too small to explore in the analysis.

Inclusion of siblings may have introduced bias, particularly if a large proportion of one drug exposed group were from one family, and an apparent drug effect may have been confounded by a genetic effect. We have explored this bias by performing the regression analysis on the first born children only. The results from these analyses were similar to those from inclusion of all children. Univariate analysis showed evidence for a decrease in children's VIQ in association with valproate exposure, five or more tonic-clonic seizures in pregnancy, and a family history of learning difficulties, in contrast to an increase with increasing maternal IQ (as measured by NART) and maternal age. However, multiple regression in this group confirmed that the main predictive factors were maternal IQ ( $\beta$ coefficient $0.600,95 \%$ CI 0.386 to $0.813, \mathrm{p}<0.001$ ), exposure to valproate in utero ( $\beta$ coefficient $-10.912,95 \%$ CI -17.785 to $-4.308, p=0.006$ ), or five or more tonic-clonic seizures ( $\beta$ coefficient -15.154 , 95\% CI -22.564 to $-7.744, p<0.001)$. Socioeconomic class as a group variable did not contribute significantly to the variance of the model though the $\beta$ coefficient for the lower socioeconomic group did reach significance ( $\beta$ coefficient -6.242 , 95\% CI -12.350 to $-0.134, p=0.045)$. This exploration showed that the significant variables had larger $\beta$ coefficients (or estimate of effect size) than those from the analysis that included all children. We would conclude that the bias from inclusion of siblings is unlikely to explain our findings.

The mean maternal IQ (100.0, 95\% CI 98.3 to 101.7) was within the average range regardless of mother's epilepsy type or drug use in pregnancy, with no significant differences between epilepsy or drug groups.

Among children exposed to VPS, 59\% had mothers with IGE while $78.8 \%$ exposed to carbamazepine had mothers with localisation related epilepsy $\left(\chi^{2}=19.613\right.$, df 5, $p=0.001)$. While this association may have prevented detection of an effect of IGE on VIQ in multivariate analysis, it would not explain the lack of association in univariate analysis.

There was no significant association between monotherapy regimes in pregnancy and seizures during pregnancy $\left(\chi^{2}\right.$ for trend $=2.838$, df $1, p=0.092$ ). Those exposed to five or more tonic-clonic seizures in pregnancy were more likely to have mothers with focal epilepsy (63.4\%) than IGE (36.6\%).

The number of children with major malformations (15), epilepsy (six), exposure to regular alcohol intake (27), and adequate folic acid (15, pre-conceptual dose of $5 \mathrm{mg}$ ) were too small to explore in a regression analysis. Exploration of exposure to folic acid at any dose in any stage of pregnancy (115) versus no exposure failed to show any association $\left(R^{2}=0.00, F=0.109, \mathrm{p}=0.742\right)$.

In general, the proportion of children of all ages with a major malformation was higher in the VPS monotherapy group (14\%) compared to the unexposed group (4\%). Of the 15 children over the age of 6 with major malformations, seven were exposed to VPS monotherapy. However, we found no evidence of an association between major malformations and low VIQ. The mean VIQ $(91.33,95 \%$ CI 84.83 to 97.84 ) in those with major malformations $(15,6 \%)$ was similar to those without $(90.6,95 \%$ CI 88.4 to 92.7$)$. Two children with malformations $(13.3 \%)$ had a VIQ below 79 . Both were

Table 5a Univariate linear regression for $\mathrm{VIQ}$

\begin{tabular}{|c|c|c|c|c|}
\hline Variable & $\mathrm{n}$ (mean; SD) & Mean VIQ (SD) & $F \dagger$ & pt \\
\hline Maternal age* & $248(26.1 ; 4.8)$ & $90.7(16.5)$ & 12.672 & 0.000 \\
\hline Maternal FSIQ (NART)* & $247(98.7 ; 11.5)$ & $90.7(16.5)$ & 69.979 & 0.000 \\
\hline \multirow[t]{3}{*}{ SES* } & Professional (reference) 48 & $98.8(19.7)$ & 8.248 & 0.000 \\
\hline & Intermediate 48 & $91.4(15.0)$ & & \\
\hline & Manual or never worked 149 & $88.1(14.8)$ & & \\
\hline \multirow[t]{2}{*}{ Epilepsy type } & Focal (reference) 166 & $92.0(16.7)$ & 1.761 & 0.186 \\
\hline & IGE 75 & $89.0(15.7)$ & & \\
\hline \multirow[t]{2}{*}{ Family history of LD in first degree relative } & None (reference) 205 & 91.5 (16.7) & 3.215 & 0.074 \\
\hline & 1 or more 44 & $86.6(15.90)$ & & \\
\hline \multirow[t]{2}{*}{ Regular smoking } & None (reference) 181 & $91.4(16.6)$ & 1.582 & 0.210 \\
\hline & Regular 68 & $88.5(16.1)$ & & \\
\hline \multirow[t]{4}{*}{ Seizures in pregnancy } & None (reference) 112 & $93.2(17.7)$ & 3.126 & 0.026 \\
\hline & None, convulsive 49 & $90.2(15.3)$ & & \\
\hline & $1-4$ tonic-clonic seizures 46 & $90.1(12.4)$ & & \\
\hline & 5 or more tonic-clonic seizures 42 & $84.4(6.8)$ & & \\
\hline \multirow[t]{5}{*}{ AED in utero } & Unexposed (reference) 80 & $90.9(6.5)$ & 3.884 & 0.004 \\
\hline & Valproate 41 & $83.6(17.1)$ & & \\
\hline & Carbamazepine 52 & $94.1(16.0)$ & & \\
\hline & Phenytoin 21 & $98.5(17.4)$ & & \\
\hline & Polytherapy 49 & $89.2(14.2)$ & & \\
\hline \multirow[t]{2}{*}{ Regular folic acid } & None (reference) 134 & $90.9(15.5)$ & 0.109 & 0.742 \\
\hline & Regular (any dose) 115 & $90.2(17.6)$ & & \\
\hline
\end{tabular}

*Significant factors in univariate regression model.

$\dagger F$ test based on type III sums of squares and $p$ values show significance of variable in model.

The continuous variables included were of normal distribution and the standardised residuals in all analysis were normally distributed.

IGE, idiopathic generalised epilepsy; LD, learning difficulties; SES, socioeconomic status. 
Table 5b Multiple linear regression for VIQ for all children

\begin{tabular}{|c|c|c|c|c|c|c|}
\hline Variable & n (mean; SD) & $\mathrm{Ft}$ & pt & $\beta$ Coefficientł & $95 \% \mathrm{Cl}$ & pł \\
\hline Maternal age & $230(26.1 ; 4.8)$ & 0.728 & 0.394 & & & \\
\hline Maternal IQ (NART)* & $230(98.7 ; 11.5)$ & 37.511 & 0.000 & 0.60 & 0.41 to 0.79 & 0.000 \\
\hline SES & $\begin{array}{l}\text { Professional (reference) } 47 \\
\text { Intermediate } 43 \\
\text { Manual or never worked } 140\end{array}$ & 0.903 & 0.407 & & & \\
\hline Family $\mathrm{Hx} L D$ in first degree relative & $\begin{array}{l}\text { None (reference) } 191 \\
1 \text { or more } 39\end{array}$ & 0.833 & 0.363 & & & \\
\hline \multirow[t]{3}{*}{ Seizures during pregnancy } & None (reference) 102 & 2.599 & 0.053 & & & \\
\hline & None, convulsive 46 & & & -2.13 & -7.47 to 3.21 & 0.432 \\
\hline & 1-4 tonic-clonic 44 & & & -4.36 & -9.75 to 1.02 & 0.112 \\
\hline Epilepsy type & $\begin{array}{l}5 \text { or more tonic-clonic* } 38 \\
\text { Focal (reference) } 159 \\
\text { IGE } 71\end{array}$ & 0.013 & 0.909 & -8.75 & -15.07 to -2.43 & 0.007 \\
\hline \multirow[t]{5}{*}{ AED exposure in utero } & None (reference) 73 & 6.378 & 0.000 & & & \\
\hline & Valproate ${ }^{*} 73$ & & & -7.36 & -13.29 to -1.44 & 0.004 \\
\hline & Carbamazepine 51 & & & 0.80 & -4.58 to 6.17 & 0.771 \\
\hline & Phenytoin 21 & & & 5.68 & -1.51 to 12.86 & 0.121 \\
\hline & Polytherapy 48 & & & 2.08 & -3.92 to 8.09 & 0.495 \\
\hline \multicolumn{7}{|c|}{$\begin{array}{l}\text { *Significant factors in multiple regression model. } \\
\dagger F \text { test based on type III sums of squares and } p \text { values show significance of variable in model. } \\
\text { fOnly the adjusted coefficients for variables that reached significance are shown. } p \text { Value for adjusted } \beta \text { coefficient (compared to reference variable for categorical } \\
\text { variables). } \\
\text { Overall model characteristics } R^{2}=0.288 \text {, adjusted } R^{2}=0.245, F=6.709 ; p=0.000, S D \text { residuals }=0.971 \text {. } \\
\text { The continuous variables included were of normal distribution and the standardised residuals in all analysis were normally distributed. Folic acid and smoking were } \\
\text { not included in the model as the univariate modelling did not suggest that that they were significant. } \\
\text { IGE, idiopathic generalised epilepsy; LD, learning difficulties; SES, socioeconomic status. }\end{array}$} \\
\hline
\end{tabular}

exposed to VPS, one had hypospadias, and the other a split hand.

\section{Exploration of dose effect}

There was no significant correlation between VIQ and drug dose for carbamazepine or phenytoin. There was a negative correlation between VIQ and VPS dose in the first trimester (Spearman's $\rho-0.399, \mathrm{p}=0.011$ ) and the whole pregnancy (Spearman's $\rho-0.293, p=0.093$ ), but the latter was not significant. Exploring this further to look for a possible threshold effect, we divided the dose range into three approximately equal portions (table 6). Doses above $800 \mathrm{mg}$ of valproate were associated with, on average, 8-15 points lower VIQ, compared to those on $800 \mathrm{mg}$ and below, though the numbers were small. The VIQ of children exposed to $800 \mathrm{mg}$ or below was similar to unexposed children.

\section{Children under age 6}

A total of 119 children aged under 6 completed the SGS assessment. A higher proportion of children exposed to VPS monotherapy and to polytherapy showed delay in some domains compared to carbamazepine exposed or unexposed children. This was particularly marked for the interaction (VPS 33.3\%, unexposed 0\%, and hearing and language domains (VPS 19\%, unexposed 0\%) (fig 2).

Table 6 Dose effect of valproate monotherapy in utero on VIQ in children

\begin{tabular}{|c|c|c|c|}
\hline & $n^{*}$ & Mean VIQ & $95 \% \mathrm{Cl}$ \\
\hline \multicolumn{4}{|c|}{ Mean AED dose in whole pregnancy } \\
\hline VPS $\leqslant 800$ & 11 & 90.7 & 80.6 to 101.4 \\
\hline VPS $801-1500$ & 23 & 82.0 & 74.3 to 89.7 \\
\hline VPS $>1500$ & 6 & 73.8 & 60.2 to 87.4 \\
\hline \multicolumn{4}{|c|}{ Mean AED dose in first trimester } \\
\hline VPS $\leqslant 800$ & 6 & 88.7 & 67.1 to 110.2 \\
\hline VPS $801-1500$ & 21 & 81.0 & 72.7 to 89.3 \\
\hline VPS $>1500$ & 7 & 75.9 & 63.8 to 87.9 \\
\hline Unexposed group & 80 & 90.9 & 87.2 to 94.6 \\
\hline
\end{tabular}

There was a significantly higher odds of any delay in those exposed to VPS monotherapy (OR 10.5, 95\% CI 1.2 to 94.5) compared to the unexposed group.

\section{AENs and therapeutic input}

It is evident that valproate exposure in monotherapy or polytherapy is associated with AENs (table 7, for children aged 4 and above). A total of 19.7\% (74) of all the children had received speech therapy input at some point. This was particularly high among the VPS monotherapy exposed group $(47.6 \%, 30)$ with the other groups being similar to the unexposed group $(15,14.6 \%)$.

Only nine children had received a specific diagnosis requiring therapeutic input. In particular, there were two with Asperger's syndrome (one VPS monotherapy, one VPS polytherapy), two with attention deficit hyperactivity disorder (both VPS monotherapy), and five with dyspraxia (two VPS monotherapy, three unexposed).

\section{Dysmorphic features and low VIQ}

The majority of children had a normal appearance or only mild dysmorphic features regardless of drug exposure. However, dysmorphic features were more commonly seen in children exposed to VPS, with $44 \%$ having moderate to severe dysmorphic features in contrast to those exposed to carbamazepine $(9.2 \%)$ and the unexposed $(2.2 \%)$.

In the children aged 6 and over, $22 \%$ of those with normal appearance had a low VIQ $(<79)$ in contrast to $55 \%$ of those with moderate to severe features. The association between VIQ and dysmorphic features was most marked in the VPS monotherapy group, which was the only group with a significant correlation (Spearman's $\rho-0.436$, 95\% CI -0.107 to $-0.827, p=0.007)$. This probably reflects the fact that the majority of those with dysmorphic features were in the VPS exposed group.

\section{DISCUSSION}

The optimal management of women with epilepsy during their childbearing years, and during their pregnancies in particular, presents a considerable clinical dilemma. It has been recognised that treatment with AEDs during pregnancy is associated with an increased risk of major congenital 


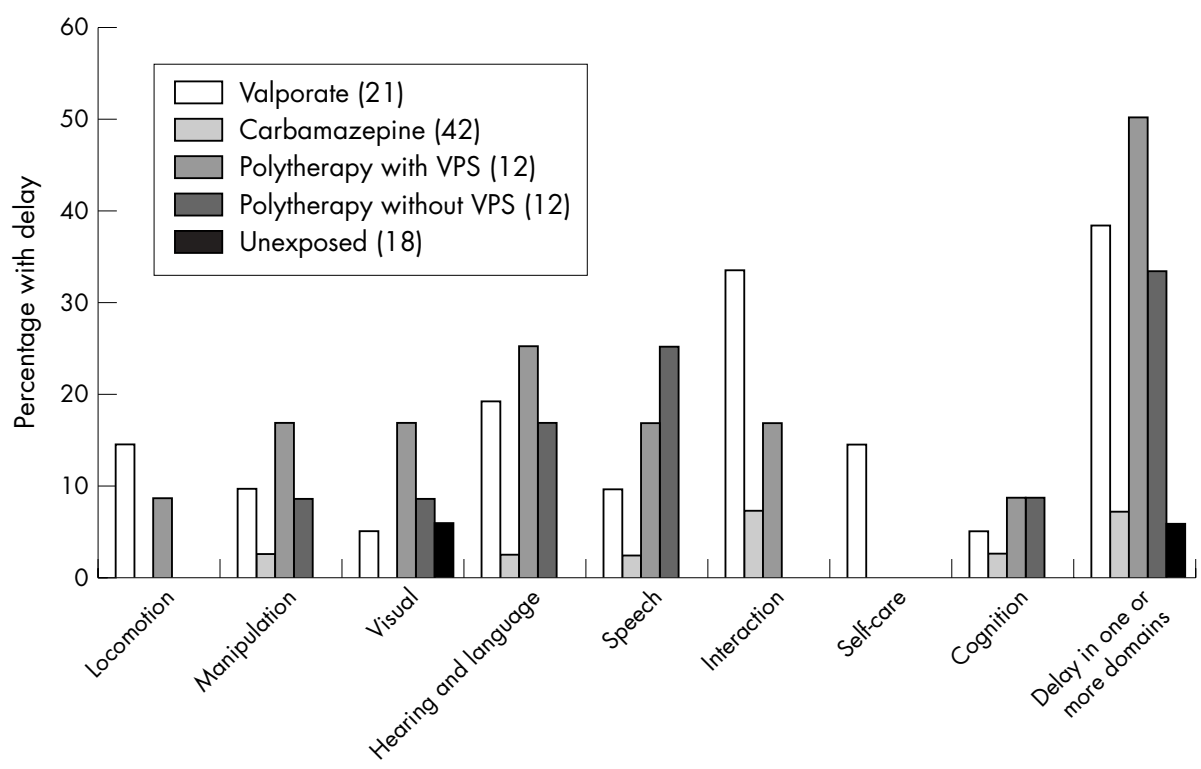

Figure 2 Percentage of children with delay in each of the domains assessed by the SGSII. Nine skill areas are assessed with a separate score for cognition. Passive posture and active posture are not shown as these are only assessed in children up to 12 months and were normal in all groups. Each skill area is scored independently and categorised as "normal" or "delayed" for the child's age.

malformation. However, the justification for treatment has been that the risks of seizures to a pregnancy are greater than those of AED therapy. This needs to be questioned. We need to define what risks we are considering and whom they might affect, mother or child?

The confidential enquiries into maternal deaths in the United Kingdom ${ }^{42-46}$ do identify women with epilepsy as being at particular risk (table 8). If it is assumed that between 1:200 and 1:250 pregnancies occur in women with a history of epilepsy, it can be calculated that the approximate odds for maternal death are 10 times higher for women with epilepsy than the general population. This seems to represent an increased mortality risk during pregnancy above the usual standard mortality rate of 2-3 for epilepsy throughout life as a whole. ${ }^{47}{ }^{48}$ The case histories in the reports suggest these are due to seizure occurrence often associated with stopping AEDs or with poor compliance. There is little literature or data to quantify any risk for malformations or other adverse outcome in the fetus from seizures. ${ }^{49}$ Inevitably, disentangling the potential effects of seizures from those of AEDs will be confounded by the fact that women with more severe epilepsy will be exposed to a higher burden of drug therapy during their pregnancies.

The main focus of research for risk to the fetus has been the risk of major congenital malformations. However, minor dysmorphic features, possibly associated with developmental delay, have been reported with most AEDs including phenytoin, ${ }^{8}$ carbamazepine, ${ }^{12}{ }^{14}$ and valproate. ${ }^{11} 13$ Though the fetal valproate syndrome was first described in $1984,{ }^{11}{ }^{13}$ the association between dysmorphism and cognitive impairment has remained unclear, including whether more subtle cognitive problems might occur in the absence of dysmorphism.
Table 8 Confidential enquiry into maternal deaths 1985-99

\begin{tabular}{lccc}
\hline Years of enquiry & Maternities* & $\begin{array}{l}\text { Direct and } \\
\text { indirect deaths }\end{array}$ & $\begin{array}{l}\text { Deaths in } \\
\text { epilepsy }\end{array}$ \\
\hline $1985-87$ & $2.27 \mathrm{~m}$ & 223 & 3 \\
$1988-90$ & $2.36 \mathrm{~m}$ & 238 & 9 \\
$1991-93$ & $2.32 \mathrm{~m}$ & 228 & 6 \\
$1994-96$ & $2.19 \mathrm{~m}$ & 68 & 19 \\
$1997-99$ & $2.12 \mathrm{~m}$ & 242 & 9 \\
TOTAL & $11.26 \mathrm{~m}$ & 1199 & 46 \\
\hline
\end{tabular}

*Number of pregnant mothers in millions.

†Maternal deaths are defined as deaths within 42 days of termination of pregnancy. Direct deaths are those are those that directly relate to the pregnancy. Indirect deaths are those that result from previous disease aggravated by pregnancy.

This study has focused on the cognitive and developmental outcomes in children born to women with epilepsy. Retrospective ascertainment through epilepsy clinics is liable to bias, being more likely to identify women with more problematic epilepsy. The relatively low level of response to participation $(40 \%)$ is likely to lead to an overestimate of the size of any observed effects. There seems little doubt that women whose children have problems were more likely to participate than those whose children are developing normally. These biases seem to be evident in the assessments of children whose mothers' pregnancies were not exposed to AEDs. We cannot exclude that this bias may operate differently for different exposures though this seems unlikely.

Table 7 Educational problems

\begin{tabular}{lcccl}
\hline AED exposure & Statement & AEN* register & Any AEN* & OR AEN* (95\% CI) \\
\hline Unexposed (87) & $7(8.0 \%)$ & $12(13.8 \%)$ & $28(32.2 \%)$ & 1.00 \\
Monotherapy & $15(30 \%)$ & $20(40 \%)$ & $24(48 \%)$ & $1.95(0.95$ to 3.97$)$ \\
$\quad$ Valproate (50) & $1(1.6 \%)$ & $5(8.2 \%)$ & $14(23 \%)$ & $0.63(0.30$ to 1.33$)$ \\
$\quad$ Carbamazepine (61) & $1(4.5 \%)$ & $3(13.6 \%)$ & $7(31.8 \%)$ & $0.98(0.36$ to 2.68$)$ \\
$\quad$ Phenytoin (22) & $1(3.8 \%)$ & $3(11.5 \%)$ & $6(23.1 \%)$ & $0.63(0.23$ to 1.75$)$ \\
Polytherapy without valproate (26) & $9(31.0 \%)$ & $10(34.5 \%)$ & $12(41.4 \%)$ & $1.49(0.63$ to 3.53$)$ \\
Polytherapy with valproate (29) & 9 & & \\
\hline *AEN, additional educational needs. & & &
\end{tabular}


The unexposed comparator group may be criticised as being an imperfect control group, but no perfect control group exists. It does offer the possibility of a limited examination of any possible genetic contribution to our results. Inevitably this group does differ in many respects from those receiving treatment, but the use of a multiple regression model has allowed us to explore some confounding factors including seizure frequency, epilepsy type, and maternal IQ.

Our results demonstrate that children exposed to sodium valproate may show a specific pattern of impairment for verbal abilities without statistically significant effects on PIQ or FSIQ. VIQ is a measure of verbal abilities and verbal comprehension, while PIQ is more a measure of non-verbal problem solving abilities. Children with severe mental retardation often have a low FSIQ, while those with a learning disability may have discrepancies between their verbal and PIQ. Reductions in mean VIQ compared to performance and FSIQ are well recognised in these groups of children. ${ }^{38}$ We have explored the implications of this in a further publication.

Similarly it is evident that younger children are already exhibiting delayed development as measured by the schedule of growing skills (SGS) including effects on speech and language. The consistency of these observations across the age groups, using different tools, argues for their validity, as does an observed dose related effect for valproate with as much as an 8-15 point difference in VIQ between children exposed to doses below $800 \mathrm{mg} /$ day of valproate compared to those exposed to higher doses. Interpretation of the dose effect is limited by small numbers, lack of information regarding compliance, or drug levels in pregnancy. However, this may be taken as soft evidence that doses below $800 \mathrm{mg}$ may be safe. In the group as a whole as well as the first born children only, exposure to valproate appears to be one of the three main determining factors of a child's VIQ along with maternal IQ and the occurrence of five or more tonic-clonic seizures during pregnancy. This latter finding is one of the first attaching a developmental risk to the occurrence of seizures during pregnancy.

Our results conflict somewhat with those of Dean et al. ${ }^{20}$ They found adverse effects with valproate, carbamazepine, and phenytoin exposure in early development using a structured questionnaire in mothers ascertained from maternity hospital records. Differences may result from the different methodologies used. The focus on valproate as a particular risk to development is in keeping with independent series, published in abstract form. ${ }^{30}{ }^{31}$ The pattern of cognitive impairments in older children, with the emphasis on impaired verbal abilities, is similar to that found in a smaller series. $^{50}$

While our results may indicate higher odds of cognitive problems due to valproate, it would be unwise to use our study to estimate the level of absolute risk, which will only be satisfactorily ascertained by a prospective study with community based ascertainment. If we assume that the $60 \%$ of the children who we were unable to examine had a similar exposure to AEDs and all had normal IQs, then $17 \%$ of all valproate exposed children would have had an IQ in the low range or below compared to an expected rate of $9 \%$ in a normal population. ${ }^{38}$ It is evident within the population studied that the verbal impairments noted have considerable consequences both in terms of demand for therapy and difficulties in schooling.

We found a consistent correlation with the degree of dysmorphism that children show and the likelihood of significant cognitive impairment. This argues that the fetal valproate syndrome constitutes a real clinical entity that includes developmental delay and cognitive impairments, but that some children might exhibit some developmental delay without marked dysmorphism.

While the mechanisms leading to the fetal valproate syndrome are uncertain, abnormalities of folate metabolism have been implicated. ${ }^{51}$ Our data cannot provide support for a protective effect for preconceptual folate, as only 15 women took adequate doses of folate in this way. While it is usually accepted that many of the risks for major malformations from AEDs are due to first trimester exposure, we have no evidence to indicate the degree to which the observed impairments might be related to first trimester exposure or indeed later exposure.

What then are we to advise women with epilepsy about pre-conceptual drug therapy? Valproate may best be avoided in women with localisation related epilepsy. Here there are a number of alternatives, including carbamazepine, that are more likely to be effective in seizure control than valproate. ${ }^{52}$

The dilemmas persist, however, for women with idiopathic generalised epilepsy. While there are no satisfactory trials comparing the efficacy of valproate to other AEDs in these syndromes, there is a clinical consensus and some open uncontrolled data indicating its superiority over other AEDs for seizure control..$^{53}{ }^{54}$ Thus, here there is a potential conflict between the desire to avoid complications from seizures and from drug therapy. Women could be offered alternative treatment with phenytoin, lamotrigine, or carbamazepine, all of which may offer some protection against tonic-clonic seizures. The inclusion of a small number of women with phenytoin in our study does not suggest any major risk of cognitive impairment, which is in agreement with other investigators, ${ }^{25}$ and it appears a relatively low risk drug for major malformations. ${ }^{355}$ Lamotrigine has been widely advocated for the treatment of women. Again it appears to be a relatively low risk antiepileptic drug for major malformations (approximately $4 \%$ ), ${ }^{55}$ but there is no evidence concerning neurodevelopmental outcomes. Carbamazepine might be considered as an alternative, but it can on occasions exacerbate other seizure types seen in the idiopathic generalised epilepsies (myoclonus and absence). The gradual withdrawal of valproate and a switch to one of these options (or indeed other newly licensed AEDs without evidence of safety in pregnancy) could be discussed with women with IGE, but if seizure control is not optimal then a combination of low dose valproate with an additional drug might be an acceptable alternative. However, there is some evidence that a valproate-lamotrigine combination carries a relatively high risk of malformation ${ }^{56}$ (Morrow, personal communication). For women with idiopathic generalised epilepsy who have enjoyed significant remission of their epilepsy, then withdrawal of AEDs may be considered, though if they have IGE the risk of recurrence within 1-2 years of withdrawal may be high. ${ }^{57}$ Ultimately, drug withdrawal involves a balance of risks, with loss of seizure control having potential implications not only for the mother and the course of her pregnancy but, as suggested by our study, her child as well. In order to allow women to make an informed choice we require more accurate data about seizure control and pregnancy outcomes. This has implications for the design of prospective studies.

The results of our study are of concern given that valproate was first licensed in the United Kingdom in 1975. The last 10 years have seen the licensing of seven new AEDs, some of which may come to be used commonly during the childbearing years. It is essential that adequately controlled prospective studies are established now to identify the level of risk for cognitive impairment in children of women taking both new and established AEDs during pregnancy.

Our data demand that epilepsy services deliver adequate information and counselling about drug treatment during childbearing years. This needs to be offered before pregnancy 
and updated regularly. Counselling might initially take place as part of an adolescent clinic transferring care from paediatric to adult services. Current services and practice would need to evolve considerably as for many women these issues are only raised when they present in the first trimester of pregnancy.

\section{Authors' affiliations}

N Adab, D W Chadwick, Department of Neurological Science, The Walton Centre for Neurology and Neurosurgery, Liverpool, UK

U Kini, J Ayres, J Clayton-Smith, Department of Clinical Genetics, St Mary's Hospital, Manchester, UK

J Vinten, G Baker, J Gorry, Department of Neuropsychology, The Walton Centre for Neurology and Neurosurgery, Liverpool

H Coyle, G Mawer, Department of Neuroscience, Central Manchester Health Care Trust, Manchester, UK

A Fryer, Department of Clinical Genetics, Alder Hey Children's Hospital NHS Trust, Liverpool, UK

J Gregg, Department of Community Paediatrics, Alder Hey Children's Hospital NHS Trust, Liverpool, UK

P Nicolaides, Department of Paediatric Neurology, Alder Hey Children's Hospital NHS Trust, Liverpool, UK

L Pickering, L Tunnicliffe, Clinical Trials Unit, The Walton Centre for Neurology and Neurosurgery, Liverpool

Competing interests: none declared

\section{REFERENCES}

1 Wallace $H$, Shorvon S, Tallis R. Age-specific incidence and prevalence rates of treated epilepsy in an unselected population of 2,052,922 and age-specific fertility rates of women with epilepsy. Lancet 1998;352(9145):1970-3.

2 Fairgrieve SD, Jackson $M$, Jonas $P$, et al. Population based, prospective study of the care of women with epilepsy in pregnancy. BMJ 2000;321(7262):674-5.

3 Holmes LB, Harvey EA, Coull BA, et al. The teratogenicity of anticonvulsant drugs. N Engl J Med 2001;344(15):1132-8.

4 Battino D, Binelli S, Caccamo ML, et al. Malformations in offspring of 305 epileptic women: a prospective study. Acta Neurol Scand 1992;85(3):204-7.

5 Samren EB, van Duijn CM, Koch S, et al. Maternal use of antiepileptic drugs and the risk of major congenital malformations: a joint European prospective study of human teratogenesis associated with maternal epilepsy. Epilepsia 1997;38(9):981-90

6 Kaneko S, Battino D, Andermann E, et al. Congenital malformations due to antiepileptic drugs. Epilepsy Res 1999;33(2-3):145-58.

7 Hill RM, Verniaud WM, Horning MG, et al. Infants exposed in utero to antiepileptic drugs. A prospective study. Am J Dis Child 1974; 127(5):645-53.

8 Hanson JW, Myrianthopoulos NC, Harvey MA, et al. Risks to the offspring of women treated with hydantoin anticonvulsants, with emphasis on the fetal hydantoin syndrome. J Pediatr 1976;89(4):662-8.

9 Hill RM, Verniaud WM, Rettig GM, et al. Relation between antiepileptic drug exposure of the infant and developmental potential. In: Janz D, Dam M, Richens $A$, et al, eds. Epilepsy, pregnancy and the child. New York: Raven Press, 1982:409-17.

10 Speidel BD, Meadow SR. Maternal epilepsy and abnormalities of the fetus and newborn. Lancet 1972;2(7782):839-43.

11 Diliberti JH, Farndon PA, Dennis NR, et al. The fetal valproate syndrome. Am J Med Genet 1984;19(3):473-81.

12 Jones KL, Lacro RV, Johnson KA, et al. Pattern of malformations in the children of women treated with carbamazepine during pregnancy. N Engl J Med 1989;320(25): 1661-6.

13 Clayton-Smith J, Donnai D. Fetal valproate syndrome. J Med Genet 1995;32(9):724-7.

14 Ornoy A, Cohen E. Outcome of children born to epileptic mothers treated with carbamazepine during pregnancy. Arch Dis Child 1996;75(6):517-20.

15 Mawer G, Clayton-Smith J, Coyle H, et al. Outcome of pregnancy in women attending outpatient epilepsy clinic: adverse features associated with higher doses of sodium valproate. Seizure 2002;11:512-8.

16 Gaily E, Granstrom ML. Minor anomalies in children of mothers with epilepsy. Neurology 1992;42(4 suppl 5):128-31.

17 Nulman I, Scolnik D, Chitayat D, et al. Findings in children exposed in utero to phenytoin and carbamazepine monotherapy: independent effects of epilepsy and medications. Am J Med Genet 1997;68(1):18-24

18 Majewski F, Steger M, Richter B, et al. The teratogenicity of hydantoins and barbiturates in humans, with considerations on the etiology of malformations and cerebral disturbances in the children of epileptic parents. Int J Biol Res Pregnancy 1981;2(1):37-45.

19 Beck-Mannagetta G, Janz D. Data on psychomotor and mental development in children of epileptic mothers: a retrospective study. In: Janz D, Dam M Richens $A$, et al, eds. Epilepsy, pregnancy and the child. New York: Raven Press, 1982:443-5.

20 Dean JC, Hailey H, Moore SJ, et al. Long term health and neurodevelopment in children exposed to antiepileptic drugs before birth. J Med Genet 2002;39(4):251-9.
21 Scolnik D, Nulman I, Rovet J, et al. Neurodevelopment of children exposed in utero to phenytoin and carbamazepine monotherapy [see comments]. JAMA 1994;271(10):767-70 [published erratum appears in JAMA 1994;271(22):1745]

22 Fujioka K, Kaneko S, Hirano T, et al. A study of the psychomotor development of the offspring of epileptic mothers. In: Sato T, Shinagawa S, eds. Antiepileptic drugs and pregnancy. Amsterdam: Excerpta Medica, 1984:196-206.

23 Leavitt AM, Yerby MS, Robinson N, et al. Epilepsy in pregnancy: developmental outcome of offspring at 12 months. Neurology 1992;42(4 suppl 5):141-3.

24 Shapiro S, Hartz SC, Siskind V, et al. Anticonvulsants and parental epilepsy in the development of birth defects. Lancet 1976;1(7954):272-5.

25 Gaily E, Kantola-Sorsa E, Granstrom ML. Intelligence of children of epileptic mothers. J Pediatr 1988;1 13(4):677-84.

26 van der Pol MC, Hadders-Algra M, Huisjes HJ, et al. Antiepileptic medication in pregnancy: late effects on the children's central nervous system development. Am J Obstet Gynecol 1991;164(1 Pt 1):121-8.

27 Wide K, Henning E, Tomson T, et al. Psychomotor development in pre-school children exposed to antiepileptic drugs. Acta Paediatr 2002;91(4):409-14.

28 Vanoverloop D, Schnell RR, Harvey EA, et al. The effects of prenatal exposure to phenytoin and other anticonvulsants on intellectual function at 4 to 8 years of age. Neurotoxicol Teratol 1992; 14(5):329-35.

29 Ornoy A, Cohen E. Outcome of children born to epileptic mothers treated with carbamazepine during pregnancy. Arch Dis Child 1996;75(6):517-20.

30 Ohtsuka Y, Silver K, Lopes-Cendes I, et al. Effect of antiepileptic drugs on psychomotor development of offspring of epileptic mothers [abstract]. Epilepsia 1999;40(suppl 2):296.

31 James $\mathrm{F}$, Lynch SA, Fairgrieve SD, et al. A prospective population based study of developmental delay and craniofacial dysmorphism in children born to women with epilepsy [abstract]. J Med Genet 2000;37(S1):S67.

32 Gaily E, Kantola-Sorsa E, Granstrom ML. Specific cognitive dysfunction in children with epileptic mothers. Dev Med Child Neurol 1990;32(5):403-14.

33 Steinhausen HC, Losche G, Koch S, et al. The psychological development of children of epileptic parents. I. Study design and comparative findings. Acta Paediatr 1994;83(9):955-60.

34 Adab N, Jacoby A, Smith D, et al. Additional educational needs in children born to mothers with epilepsy. I Neurol Neurosurg Psychiatr $2001 ; 70(1): 15-21$.

35 Commission on Classification and Terminology of the International League Against Epilepsy. Proposal for revised classification of epilepsies and epileptic syndromes. Epilepsia 1989;30:389-99.

36 Moore SJ, Turnpenny P, Quinn A, et al. A clinical study of 57 children with fetal anticonvulsant syndromes. J Med Genet 2000;37(7):489-97.

37 EUROCAT Guide 1.2, University of Ulster, 2002. http:// www.eurocat.ulster.ac.uk/ (accessed 1 August 2004)

38 Wechsler D, Golombok S, Rust J. Wechsler Intelligence Scale for Children, 3rd ed. UK Manual. Sidcup, UK: The Psychological Corporation, 1992.

39 Bellman M, Lingam S, Aukett A. Schedule of Growing Skills (SGS II) manual. UK: NFER-NELSON, 1996

40 Nelson HE. National Adult Reading Test (NART): test manual, 2nd ed. UK: NFER-NELSON, 1982

41 The National Statistics Socio-economic Classification (NS-SEC), 2001. http:// www.statistics.gov.uk/methods_quality/ns_sec/default.asp (accessed 1 August 2004)

42 Department of Health, Welsh Office, Scottish Home and Health Department, and Department of Health and Social Services Northern Ireland. Report on confidential enquiry into maternal deaths in the UK, 1985-1987. London: HMSO, 1989.

43 Department of Health, Welsh Office, Scottish Home and Health Department, and Department of Health and Social Services Northern Ireland. Report on confidential enquiry into maternal deaths in the UK, 1988-1990. London: HMSO, 1992.

44 Department of Health: Welsh Office, Scottish Home and Health Department, and Department of Health and Social Services Northern Ireland. Report on confidential enquiry into maternal deaths in the UK, 1991-1993. London: HMSO, 1995.

45 Department of Health, Welsh Office, Scottish Home and Health Department, and Department of Health and Social Services Northern Ireland. Why mothers die - report on confidential enquiry into maternal deaths in the UK, 1994-1996. London: The Stationery Office, 1998

46 The Scottish Executive Health Department, The National Institute for Clinical Excellence, The Department of Health, Social Services and Public Safety: Northern Ireland. Why mothers die - report on confidential enquiry into maternal deaths in the UK, 1997-1999. London: RCOG Press, 2001.

47 Hauser WA, Hesdorffer DC. Epilepsy: frequency, causes and consequences. New York: Demos Publications, 1990

48 Lhatoo SD, Johnson AL, Goodridge DM, et al. Mortality in epilepsy in the first 11 to 14 years after diagnosis: multivariate analysis of a long-term, prospective, population-based cohort. Ann Neurol 2001;49(3):336-44.

49 Shorvon S. Antiepileptic drugs in pregnancy: the neurologist's perspective. J Med Genet 2002;39:248-250.

50 Gaily E, Kantola-Sorsa E, Hiilesmaa V, et al. Normal intelligence in children with prenatal exposure to carbamazepine. Neurology 2004;62(1):28-32.

51 Dean JCS, Moore SJ, Osborne A, et al. Fetal anticonvulsant syndrome and mutation in the maternal MTHFR gene. Clin Genet 1999;56(3):216-20.

52 Marson AG, Williamson PR, Clough $\mathrm{H}$, et al. Carbamazepine versus valproate monotherapy for epilepsy: a meta-analysis. Epilepsia 2002;43(5):505-13. 
53 The Scottish Intercollegiate Guidelines Network (SIGN). Guideline 70. http://www.sign.ac.uk/guidelines/published/index.html (accessed 9 August 2004).

54 Nicolson A, Appleton R, Chadwick D, Smith D. Relationship between treatment with valproate, lamotrigine and topiramate and the prognosis of the idiopathic generalised epilepsies. J Neurol Neurosurg Psychiatr 2004;75(1):75-9
55 Craig J, Russell A, Parsons L, et al. The UK Epilepsy and Pregnancy Register: update of results 1996-2002 [abstract]. Epilepsia 2002;43(S8):56

56 Tennis P, Eldridge RR, and the International Lamotrigine Pregnancy Registry Scientific Advisory Committee. Preliminary results on pregnancy outcomes in women using lamotrigine. Epilepsia 2002:43(10):1161-7.

57 Delgado-Escueta AV, Enrile-Bacsal F. Juvenile myoclonic epilepsy of Janz. Neurology 1984;34:285-94.

HISTORICAL NOTE

\section{A note on Pierre Marie (1853-1940)}

$t$ is perhaps a reflection of the great pace of medical advance in the 19th and early 20th century that Charcot, Gowers, Foix, Parkes Weber, and others had so many diseases to commemorate their names. Much has been written about the merits and drawbacks of eponyms ${ }^{1}$ but the habit lingers. For assiduous collators, one of the most impressive lists attributed to a single individual is associated with Pierre Marie.

Pierre Marie was born of a wealthy Parisian family. He attended a boarding school in Vauves. Under coercion from his father he read law before deciding on a medical career. He became an intern in 1878 and under the spell of Charcot soon developed an interest in nervous diseases at the Salpêtrière and Bicêtre. An outstanding student, he worked as special clinical assistant. In 1883 he received his doctorate with a dissertation on Basedow's disease, $\uparrow$ which included his observations on static tremor of the outstretched arms in hyperthyroidism. He described the neurological sequelae of exanthemata, including neurological symptoms complicating smallpox, which he attributed to insular sclerosis (multiple sclerosis), which we would recognise as post-infective encephalomyelitis. He was promoted to agrégé at the Paris Faculty of Medicine in 1889 where he delivered a remarkable series of lectures on diseases of the spinal cord, ${ }^{3}$ published in 1892, that included a comprehensive account of amyotrophic lateral sclerosis and tabes. Pierre Marie published pathological studies in two acromegalic patients in $1886,{ }^{4}$ establishing its clinicopathological status ${ }^{5}$ to which his name is linked; he mentioned Saucerotte's earlier report.

He was also, with Charcot and Tooth, ${ }^{6}$ the first to define familial peroneal muscular atrophy $(\mathrm{HMSN})^{7}$ in 1886; pulmonary hypertrophic osteoarthropathy ${ }^{8}$ (MarieBamberger disease); cerebellar heredo ataxia"; cleidocranial dysostosis; and ankylosing spondylitis, ${ }^{10}$ originally reported by Strümpell (1884) and Bechterev, and known as Marie Strümpell disease.

In 1897 Marie was appointed to the Hospice de Bicêtre, where he instigated a neurological service of international repute. There, he critically studied the aphasiacs (L'évolution du langage considéré au point de vue de l'étude de l'Aphasie, 1897) and was opposed to the views both of Broca (1824-1880) and Wernicke (1848-1905) on the localisation of speech. In a crushing critique he assailed the work of Broca, under the provocative title of The third left frontal convolution has no special role in the function of language. Re-examining Broca's original specimen, he showed that the lesion extended considerably beyond Broca's area. His three papers on aphasia appeared in 1906 in Semaine Médicale. This controversy provoked three designated sessions of the Société Française de Neurologie de Paris convened in 1908 to debate the arguments.

tHyperthyroidism, goitre, and exophthalmos were first described by the English physician Caleb Hillier Parry in 1786 and 1815, but are named in Europe after Carl Adolph von Basedow whose report was in 1840, and in England after Robert Graves 1835. (See ref 2) doi: 10.1136/jnnp.2003.024729

However, his work on aphasia dwindled after he obtained, in 1907, the Chair of Pathological Anatomy. Charles Foix continued it until his early death aged 45 . Marie devoted his energies to advancing both pathology and its teaching, greatly helped by Gustave Roussy, who would succeed him. Not until 1918, aged 64, was Marie appointed to Charcot's Chair of Neurology at Salpêtrière, recently occupied by Fulgence Raymond, Édouard Brissaud, and Joseph Jules Dejerine. But the first world war had taken its toll. Laboratory facilities had not been maintained. The neurologists of the Charcot school had been preoccupied by the investigation and treatment of war injuries. Not surprisingly, Marie's original work declined, but his Neurologie two volumes, 1923, was deservedly admired.

A brilliant clinician rooted firmly in the tradition of Charcot, Marie was an outstanding, demanding teacher, yet courteous and dignified. Percival Bailey ${ }^{11}$ described him "at his best in clinical consultation in which his discussions were short and pithy; his teaching was simple, clear, with plain exposition".

Although he received many honours Marie was a private man of independent means. He avoided publicity but remained involved in Revue Neurologique, which he had founded in 1893 with Brissaud, and the Société Française de Neurologie, which he had served as first secretary. He was a member of the Académie de Médecine. After resigning his chair in 1925, aged 72, he retired to his estate on the Côte d'Azur where he wrote Travaux et mémoires, 1926 and 1928.

But his life was saddened by the death of his wife from erysipelas and his only son from botulism contracted at work in the Pasteur Institute. After this, he lived a solitary existence and died aged 86.

J M S Pearce

304 Beverley Road, Analby, HULL HU10 7BG, UK; jmspearce@freenet.co.uk

\section{References}

1 Koehler P, Bruyn G, Pearce JMS. Neurological eponyms. New York: Oxford University Press, 2000.

2 Major RH. Classic descriptions of disease. 3rd edn. Springfield, Illinois: Charles C Thomas, 1965.

3 Marie P. Lecons sur les maladies de la moelle. Paris: Masson, 1892 [English translation Montagu Lubbock. London: The New Sydenham Society, 1895;CLII.].

4 Marie Pierre. Sur deux cas d'acromegalie. Hypertrophe singuliere no congénitale des extrémités supérieures, inférieures et cephalique. Révue Médicale Française 1886;6:297-333.

5 Peacrce JMS. Acromegaly (Pierre Marie's disease). In: Fragments of neurological history. London: Imperial College Press, 2003:501-9.

6 Pearce JMS. Howard Henry Tooth (1856-1925). J Neurol 2000;247:3-4.

7 Charcot JM, Marie P. Sur une forme particulière d'atrophie musculaire progressive souvent familiale débutant par les pieds et les jambes et atteignant plus tard les mains. Rev Méd Paris 1886;6:97-138.

8 Marie P. De l'ostéo-arthropathie hypertrophiante pneumonique. Rev Méd 1890;10:1-36.

9 Marie P. Sur l'hérédo-ataxie cérébelleuse. Sem Méd Paris 1893;13:444-7

10 Marie P. Sur la spondylose rhizomélique. Rev Med 1898;18:285-315.

11 Bailey P. In: Webb Haymaker, Francis Schiller, eds. The founders of neurology. 2nd edn. Springfield: Charles C Thomas, 1970:476-9. 